\title{
Sleep and Obesity
}

\author{
Chenzhao Ding', Lee Ling Lim ${ }^{1,2}$, Li Xu', Alice Pik Shan Kong 1,* \\ ${ }^{1}$ Department of Medicine and Therapeutics, Prince of Wales Hospital, The Chinese University of Hong Kong, Hong Kong, China; ${ }^{2}$ Department of Medicine, Faculty of \\ Medicine, University of Malaya, Kuala Lumpur, Malaysia
}

Rising global prevalence and incidence of obesity lead to increased cardiovascular-renal complications and cancers. Epidemiological studies reported a worldwide trend towards suboptimal sleep duration and poor sleep quality in parallel with this obesity epidemic. From rodents and human models, it is highly plausible that abnormalities in sleep, both quantity and quality, impact negatively on energy metabolism. While excess dietary intake and physical inactivity are the known drivers of the obesity epidemic, promotion of healthy sleep habits has emerged as a new target to combat obesity. In this light, present review focuses on the existing literature examining the relationship between sleep physiology and energy homeostasis. Notably, sleep dysregulation perturbs the metabolic milieu via alterations in hormones such as leptin and ghrelin, eating behavior, neuroendocrine and autonomic nervous systems. In addition, shift work and trans-meridian air travel may exert a negative influence on the hypothalamic-pituitary-adrenal axis and trigger circadian misalignment, leading to impaired glucose tolerance and increased fat accumulation. Amassing evidence has also suggested that uncoupling of the circadian clock can increase the risk of adverse metabolic health. Given the importance of sleep in maintaining energy homeostasis and that it is potentially modifiable, promoting good sleep hygiene may create new avenues for obesity prevention and treatment.

Key words: Sleep, Energy metabolism, Leptin, Ghrelin, Pituitary-adrenal system, Circadian rhythm
Received February 28, 2018

Reviewed March 8, 2018

Accepted March 9, 2018

*Corresponding author

Alice Pik Shan Kong

https://orcid.org/0000-0001-8927-6764

Department of Medicine and Therapeutics, Prince of Wales Hospital, The Chinese University of Hong Kong, Shatin, NT, Hong Kong SAR, China Tel: +852-3505-1558

Fax: +852-2637-3852

E-mail: alicekong@cuhk.edu.hk

The first two authors contributed equally to this study.

\section{INTRODUCTION}

The global prevalence of obesity has doubled since 1980, affecting 107.7 million children and 603.7 million adults in 2015, with more than two-thirds of the United States population being either overweight or obese. ${ }^{1}$ This rapid surge in obesity is driven mainly by lifestyle factors such as physical inactivity, unhealthy dietary choices and patterns. ${ }^{2}$ Emerging evidence suggests that sleep disturbances (e.g., suboptimal sleep duration, poor sleep quality, circadian misalignment and insomnia), may contribute to obesity and type 2 diabetes mellitus (T2DM). ${ }^{2}$ Physiologically, sleep duration declines during transition from infancy, puberty to late adulthood. ${ }^{3}$ Optimal sleep duration has been a matter of controversy but recent consensus of the American Academy of Sleep Medicine defines short sleep duration as $<8-10$ hours and $<7$ hours per day in adolescents and adults aged 18-60 years respectively, considering the potential risks in association with the development of cardiometabolic disease and death. ${ }^{4-6}$ Due to increasing demand from school, work and leisure activities ${ }^{2}$, along with the prevalent usage of Internet and electronic devices, there is a global phenomenon for a shift in both adolescents and adults to have shorter sleep duration compared to a few decades ago. Based on the 2014 U.S. Behavioral Risk Factor Surveillance System, more than one-third of adults were short sleepers, particularly prevalent in those who were young, obese (body mass index $[\mathrm{BMI}] \geq 30 \mathrm{~kg} / \mathrm{m}^{2}$ ) or with low socioeconomic and education status. ${ }^{7}$ In China, a meta-analysis of 17 crosssectional population-based studies reported that every one in six adults had insomnia, which was again more commonly seen in

Copyright (C) 2018 Korean Society for the Study of Obesity

(a) This is an Open Access article distributed under the terms of the Creative Commons Attribution Non-Commercial License (http://creativecommons.org/licenses/by-nc/4.0/) which permits unrestricted non-commercial use, distribution, and reproduction in any medium, provided the original work is properly cited. 
young individuals. ${ }^{8}$ Paradoxically, long sleep duration ( $>9$ hours per day) was also observed in $23 \%-37 \%$ of the general population in developed countries ${ }^{9}$, and a meta-analysis of 137 prospective cohort studies reported a dose-response relationship with incident cardiovascular disease and death, attesting a U-shaped relationship between sleep duration and health outcomes across all age groups..$^{10,11}$ Alarmingly, poor sleep quality (defined as global Pittsburgh Sleep Quality Index score $>5$ ) was also independently associated with an increase in BMI and worse glycemic control. ${ }^{6}$ Given that obesity is closely linked to multiple chronic diseases, notably diabetes and cancer which are the leading causes of morbidities and mortality in many parts of the world ${ }^{12}$, the perplexing relationship between sleep and energy metabolism call for more research and clinical attention, as sleep is an essential part of life and a potentially modifiable behavioral risk factor for metabolic health. Here, we review some of the important findings in this field, and discuss the mechanisms linking sleep, energy metabolism and obesity.

\section{SLEEP AND NEUROHORMONAL DYSREGULATION}

\section{Sleep and satiety}

The appetite center, located at the ventromedial and arcuate nuclei of the hypothalamus, is regulated by hormones including leptin and ghrelin. Leptin is an adipocyte-derived hormone which suppresses appetite, whilst ghrelin is mainly a stomach-derived hungerpromoting peptide. ${ }^{13,14}$ High total energy and fat intake, night-time snacking and binge eating tendencies have been reported to be associated with sleep curtailment. ${ }^{15,16}$ The potential mechanisms mediating the effects of sleep debt on obesity are complex, which include alterations in eating behavior (e.g., skipping meals, snacking, and irregular meal times), increased ghrelin to leptin ratio and activation of hedonic pathways. ${ }^{15,17,18}$ Several small scale experimental studies involving the healthy population (number of subjects, 11 to 26 in each study) examined the effect of sleep restriction on dietary intake and patterns under the controlled environment, which included objective sleep measurements and planned meals in both phases of short and habitual sleep. ${ }^{19,20}$ Sleep restriction was reported to be associated with an increase in total energy, total fat and saturated fatty acids intake ${ }^{19}$, as well as high consumption of carbohy- drate-rich night-time snacks. ${ }^{20}$ These were accompanied by a lack of compensatory increase or even with a reduction in 24-hour energy expenditure, leading to positive energy balance. ${ }^{19,20}$ In keeping with these findings, an inverse relationship between sleep duration and total energy and macronutrient intake was evident in epidemiological cohorts. ${ }^{15,17,21,22}$ In a meta-analysis of 14,906 Europeans from the Cohorts for the Heart and Aging Research in Genomic Epidemiology Consortium, younger people (aged 20-64 years) with short sleep duration were independently associated with higher relative saturated fatty acids intake, whereas older women (aged 65-80 years) with similar exposure demonstrated higher relative carbohydrate, lower relative total fat and polyunsaturated fatty acids consumption. ${ }^{22}$ In the 2005-2010 U.S. National Health and Nutrition Examination Survey involving 15,199 community-dwelling adults, short sleepers reported frequent snacking and increased total glucose intake. ${ }^{17}$ Similarly, amongst 2,828 Chinese adults, those with less than 7-hour sleep had excess fat intake than the group with 7- to 9-hour sleep. ${ }^{21}$

Accumulating evidence suggests that sleep disruption may interfere with the feeding and satiety signals at the hypothalamic feeding circuits. ${ }^{23} \mathrm{~A}$ shift towards increased hunger in short sleepers was driven by decreased leptin level with or without a concomitant change in the diurnal rhythm amplitude of leptin, increased ghrelin level or both. ${ }^{24,25}$ In healthy young adults with stable caloric intake and activity levels, 6 days of sleep restriction (4 hours in bed per night) was independently associated with a $26 \%$ reduction in leptin than sleep extension (12 hours in bed per night), on top of a flattened diurnal profile of leptin secretion. ${ }^{25}$ In the prospective Wisconsin Sleep Cohort Study involving 1,024 healthy adults, compared with those with 8-hour of sleep, short sleepers (5-hour of sleep per day) had a $16 \%$ decrease in leptin and $15 \%$ increase in ghrelin level..$^{24}$ Interestingly, diminished activity of the appetitive desire and food stimulus evaluation regions within the frontal, insular and cingulate cortices, along with enhanced activity of amygdala are other plausible pathways linking sleep curtailment to obesity. ${ }^{26-28}$ The disrupted neural circuits led to hedonic hunger and preferences for highly palatable and rewarding energy-dense foo ${ }^{26-28}$, albeit with inter-individual variation in the magnitude of change in eating behavior proportional to the severity of sleep curtailment. ${ }^{26}$ On the other hand, short sleepers have prolonged wakefulness that 
promotes obesogenic eating behavior e.g., meal-skipping, frequent snacking and increase intake of low-quality diet. ${ }^{17,29,30}$ Late-time eating, which was defined as caloric intake after 8:00 PM, also significantly predicted an increase in BMI, suggesting that eating late at night may lead to obesity. ${ }^{29}$ Moreover, decreased nocturnal ghrelin levels were found in men with insomnia compared with their ageand body weight-matched healthy control $(n=25)$, while no difference of leptin levels was found between groups. ${ }^{31}$

\section{Sleep and growth hormone-insulin like growth factor-1} axis

The growth hormone (GH)-insulin like growth factor-1 (IGF-1) axis also plays a role in the regulation of adiposity and glucose homeostasis. Under a normal sleep/wake cycle, there is a spontaneous nocturnal GH pulse during the restorative slow wave sleep (SWS) that occurs within the first 3 hours of sleep, with both demonstrating a dose-dependent relationship. ${ }^{32}$ Increasing evidence suggests that there are biological interactions of GH/IGF-1 axis with sleep dysregulation. Sleep curtailment and late chronotype are associated with suppressed GH and IGF-1 pulsatility, followed by a compensatory increase in IGF-binding protein 3 (IGFBP-3) level via the negative feedback loop. ${ }^{33}$ In a 4-year prospective cohort study of normoglycemic adults, low circulating IGF-1 level had a $50 \%$ excess risk of developing either impaired glucose tolerance or T2DM, consequent to decreased peripheral insulin sensitivity and hyperinsulinemia. ${ }^{34}$ In the Danish-Monitoring Trends in Cardiovascular Diseases study, after a mean follow-up of 15 years, either a low IGF-1 or high IGFBP-3 level was independently associated with a relative risk (RR) of 1.94-2.22 of incident coronary heart disease, after adjustment for other cardiovascular risk factors. ${ }^{35} \mathrm{Sev}-$ eral mechanisms were postulated to explain the pleiotropic effects of GH/IGF-1 axis on the retardation of atherosclerosis e.g., reduced systemic and vascular oxidative stress (low interleukin-6 and tumor necrosis factor-alpha levels), decreased aortic stiffness and control of de novo hepatic lipid metabolism..$^{35,36}$

In contrast to the aforementioned findings, another experimental sleep restriction ( 4 hours in bed per night for six consecutive nights) study involving 11 healthy young men revealed a biphasic pattern of nocturnal GH release, with the first pulse occurred at 3-hour prior to the sleep onset and the second peak corresponded to the usual circadian rhythm as seen during the sleep extension period ( 12 hours in bed per night for a week). ${ }^{32}$ This prolonged exposure to elevated $\mathrm{GH}$ level may interact with the hunger-promoting ghrelin centrally or stimulate peripheral glucose and lipid catabolism, resulting in insulin resistance and positive energy balance. ${ }^{37}$ These findings were supported by some but not all observational studies, which reported a U-shaped relationship between IGF-1 to IGFBP-3 ratio, anthropometric traits (e.g., BMI and waist circumference) or risk of metabolic syndrome. ${ }^{38,39}$ To this end, a better understanding of the cellular-microenvironment interactions and their downstream signaling cascades integrating sleep, GH/IGF-1 axis and metabolic functions is warranted.

\section{Sleep and hypothalamic-pituitary-adrenal axis}

Sleep disturbances, including short sleep, sleep debt, and circadian misalignment, may also disrupt glucose homeostasis and cause metabolic perturbations via other hormonal and cellular signaling cascades. ${ }^{23,24,40}$ In a pilot study conducted in 11 healthy young men, decreased glucose tolerance, increased evening cortisol level and sympathetic over-activity were observed after sleep restriction (4 hours in bed per night for six consecutive nights) compared with the measurements taken after a sleep-restorative period (12 hours in bed per night for seven consecutive nights), indicating that sleep debt had a detrimental effect on glucose metabolism and endocrine function. ${ }^{40}$

The bidirectional relationships between sleep and the activity of hypothalamic-pituitary-adrenal (HPA) axis may exert negative metabolic consequences. Dysregulation of the HPA axis and its circadian rhythm can mediate the impact of sleep disturbances on cardiometabolic risk, mainly via the actions of two counter-regulatory hormones, namely the glucocorticoids and catecholamines. Physiologically, cortisol level peaks after 30-45 minutes of awakening (defined as cortisol awakening response [CAR]), followed by a sharp decline over the next 3 hours, more gradual decline over the rest of the day, and reaching nadir during the first half of sleep cycle. ${ }^{41}$ Existing studies examining the associations between sleep and circadian variability of cortisol secretion is inconclusive, due to differences in the sleep measurements (actigraphy/polysomnography vs. self-reported sleep parameters), definitions used for sleep duration and quality, and the number of real-time sampling points for 
modelling of 24-hour cortisol profile. Several reports indicated that short sleepers have flattened diurnal cortisol slope and raised evening cortisol followed by an aggravated CAR, yielding an increase in total daily cortisol secretion which ends up in a state of hypercortisolism and catabolism..$^{42-44}$ In school-age children, high CAR and subsequent diurnal cortisol level were inversely associated with short sleep duration, low sleep efficiency and low frequency of SWS. ${ }^{45,46}$ Conversely, two other studies found no association between objective sleep duration and salivary awakening $\operatorname{cortisol}^{44}$ or 24-hour urinary cortisol level. ${ }^{47}$ Poor sleep quality has been reported to be an independent stressor for excess cortisol and catecholamines secretion, particularly with greater magnitude in adolescents at late puberty. ${ }^{42,44}$ Increased HPA axis activation has also been reported in subjects with insomnia. ${ }^{48,49}$ Furthermore, it has been suggested that a gender difference on this stress reaction related to sleep disturbances which may be modulated by the type of sleep disorders involved, calling for more studies to investigate the impact of sex hormones on sleep and energy balance. ${ }^{44,50}$

Sympathetic over-activity may also contribute to the neurohormonal dysregulation linking sleep curtailment to energy imbalance. In addition to a 1.5-hour delay in the nocturnal nadir of cortisol level, experimental sleep restriction with 4 hours in bed per night for six consecutive nights in healthy volunteers had shown a concomitant 24-hour lowering of heart rate variability (measured by the autocorrelation coefficient of consecutive interbeat intervals) especially during awakening, which reflected an increase in cardiac sympathetic activity and/or diminished vagal tone, compared with sleep extension phase ( 12 hours in bed per night for seven consecutive nights). ${ }^{25}$ Physiologically, sleep onset is associated with decreased catecholamines release, reaching a nocturnal nadir an hour into a restful sleep. ${ }^{51}$ Amongst short sleepers, the secretion of norepinephrine was pathologically elevated during early awakening in early morning, between 3:00 AM and 6:00 AM, with epinephrine showing a similar trend. ${ }^{44,51}$ Furthermore, patients with mild to moderate hypertension with acute sleep restriction reported an early morning elevation in blood pressure (systolic blood pressure of $7 \mathrm{mmHg}$ and diastolic blood pressure of $4 \mathrm{mmHg}$ ) and heart rate ( 5.5 beats per minute) with potential risk of silent cardiovascular event, as sequelae of their blunted nocturnal dipping related to a surge in norepinephrine release. ${ }^{52}$

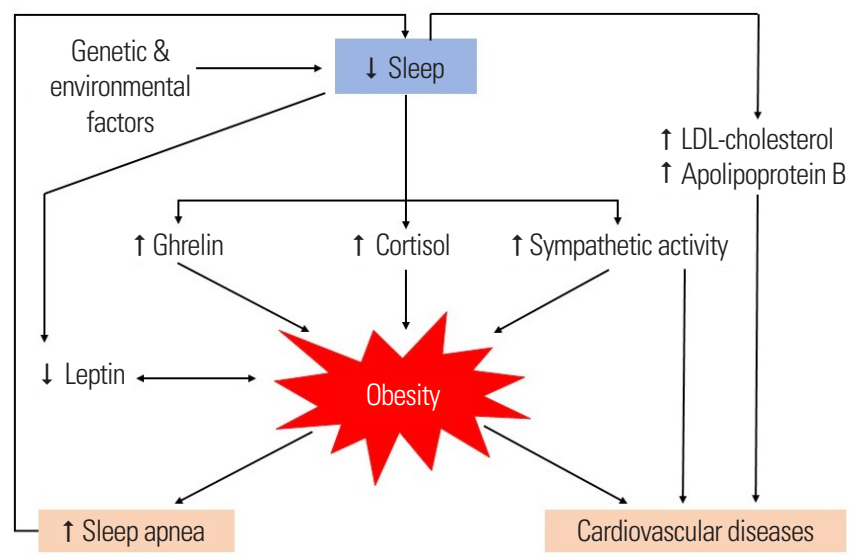

Figure 1. Association between sleep, obesity, cardiovascular risks and possible underlying neurohormonal dysregulation. LDL, low-density lipoprotein.

\section{SLEEP, OBESITY AND DIABETES}

Multiple studies have consistently demonstrated significant associations between sleep curtailment with decreased resting and postprandial energy expenditure ( $\sim 5 \%$ and $20 \%$, respectively), increased appetite and insulin resistance in general population., ${ }^{2,11}$ In addition, a randomized cross-over study demonstrated a 30\% decrease in the intracellular insulin sensitivity within adipocytes from the subcutaneous fat samples of seven healthy adults collected after sleep restriction compared with after normal sleep. ${ }^{53}$ It has also been demonstrated that short sleep duration is associated with atherogenic dyslipidemia. ${ }^{54,55}$ Once obesity sets in, there may be a vicious cycle as obesity associated comorbidities such as obstructive sleep apnea may further compromise sleep quality in affected individuals (Fig. 1). Taken together, evidence to date suggests that sleep curtailment affects the resiliency of neurohormonal stress response and predisposes to metabolic disturbances with possible long-term cardiovascular risk. Besides sleep curtailment, there have been a wealth of clinical evidence supporting the association of sleep disturbances, both quantity and quality, with obesity and diabetes (Tables 1 and 2). ${ }^{11,56-103}$ However, the associations of insomnia with obesity and glucose metabolism is under debate.

Insomnia is a common sleep problem worldwide and affects $15 \%$ of the Chinese population. ${ }^{8}$ It is defined as difficulty in initiating sleep (DIS), difficulty in maintaining sleep (DMS) and/or early morning awakening (EMA) at least three times per week with associated impairment of daytime functioning. ${ }^{104}$ Nonrestorative 


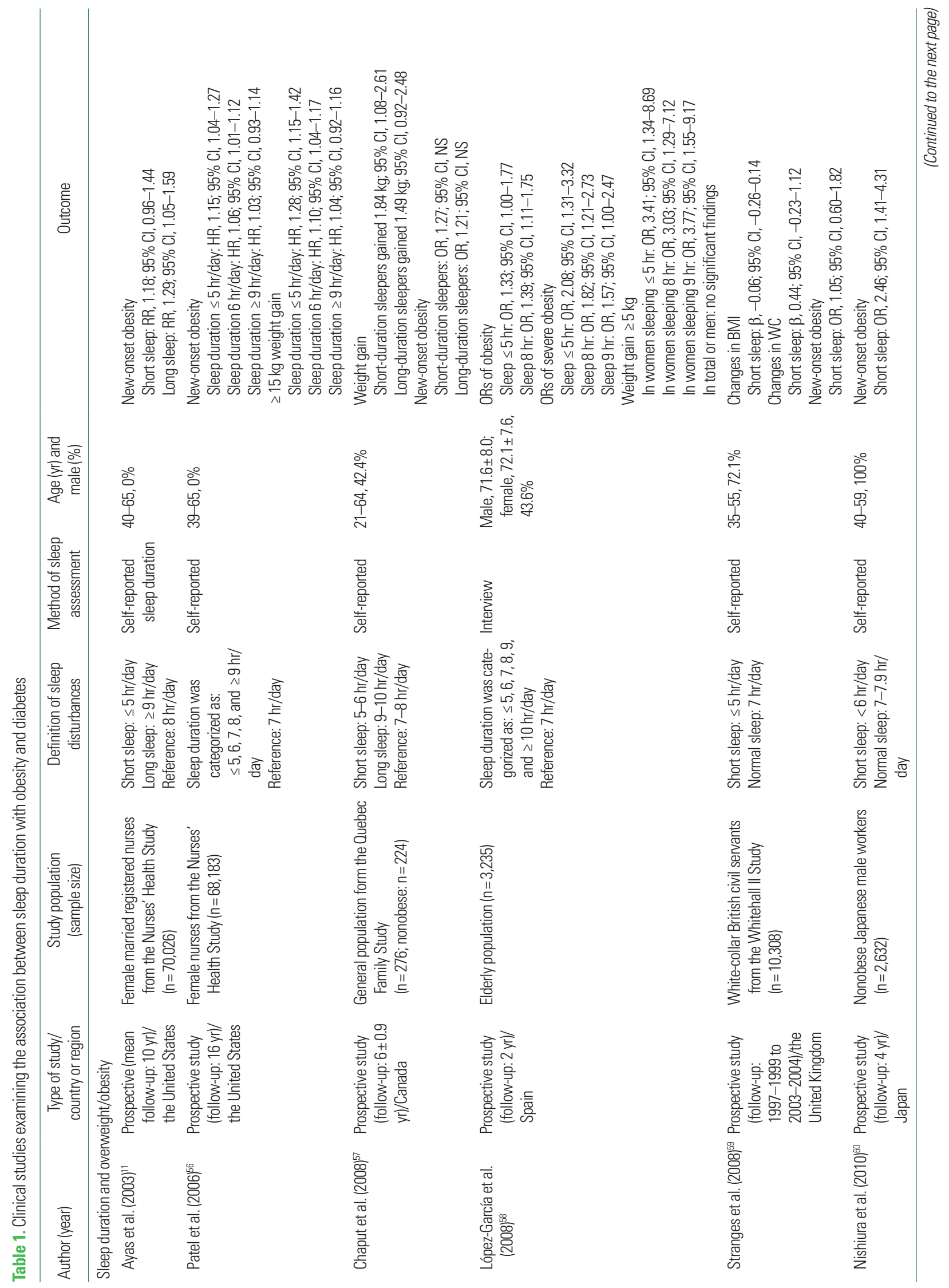




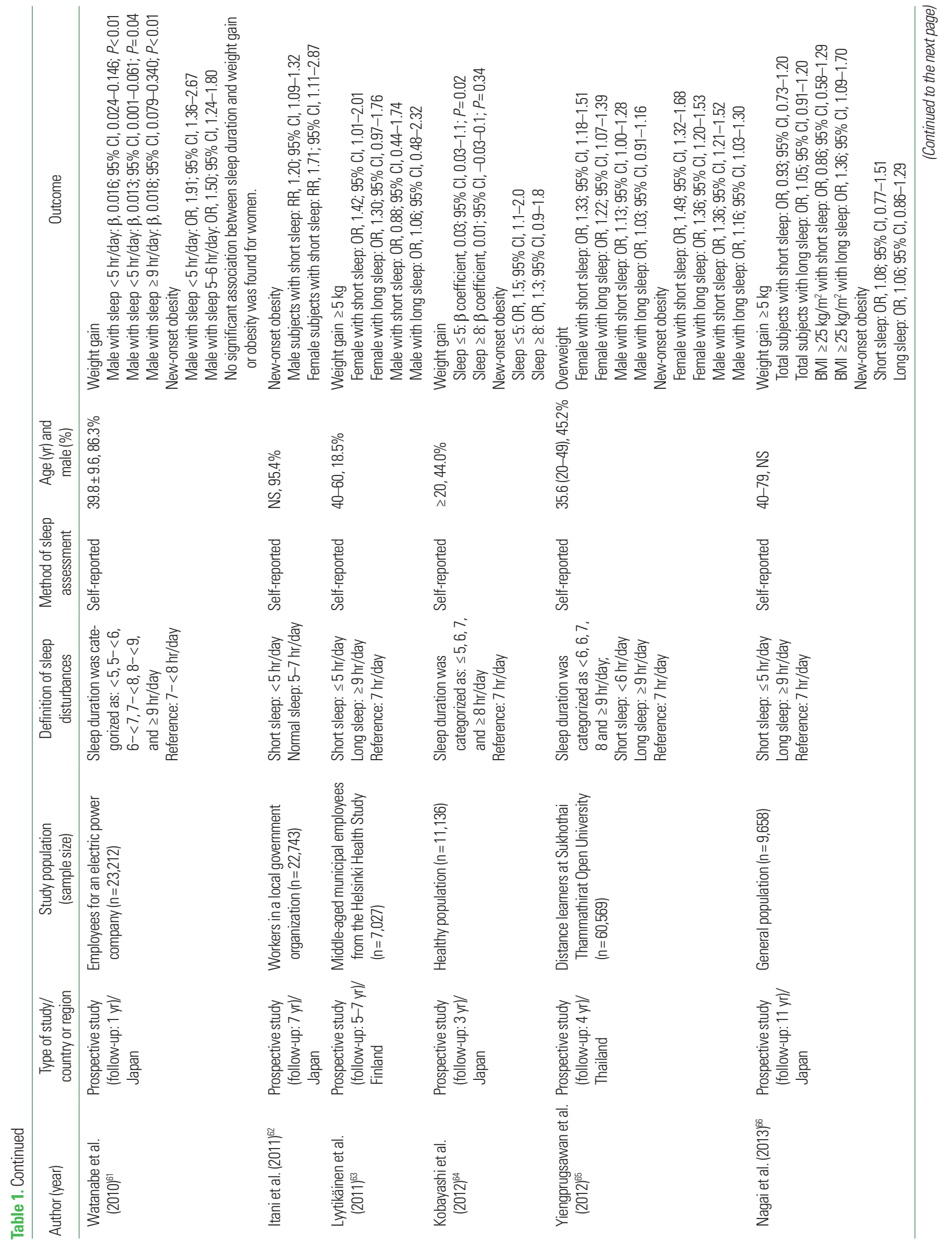




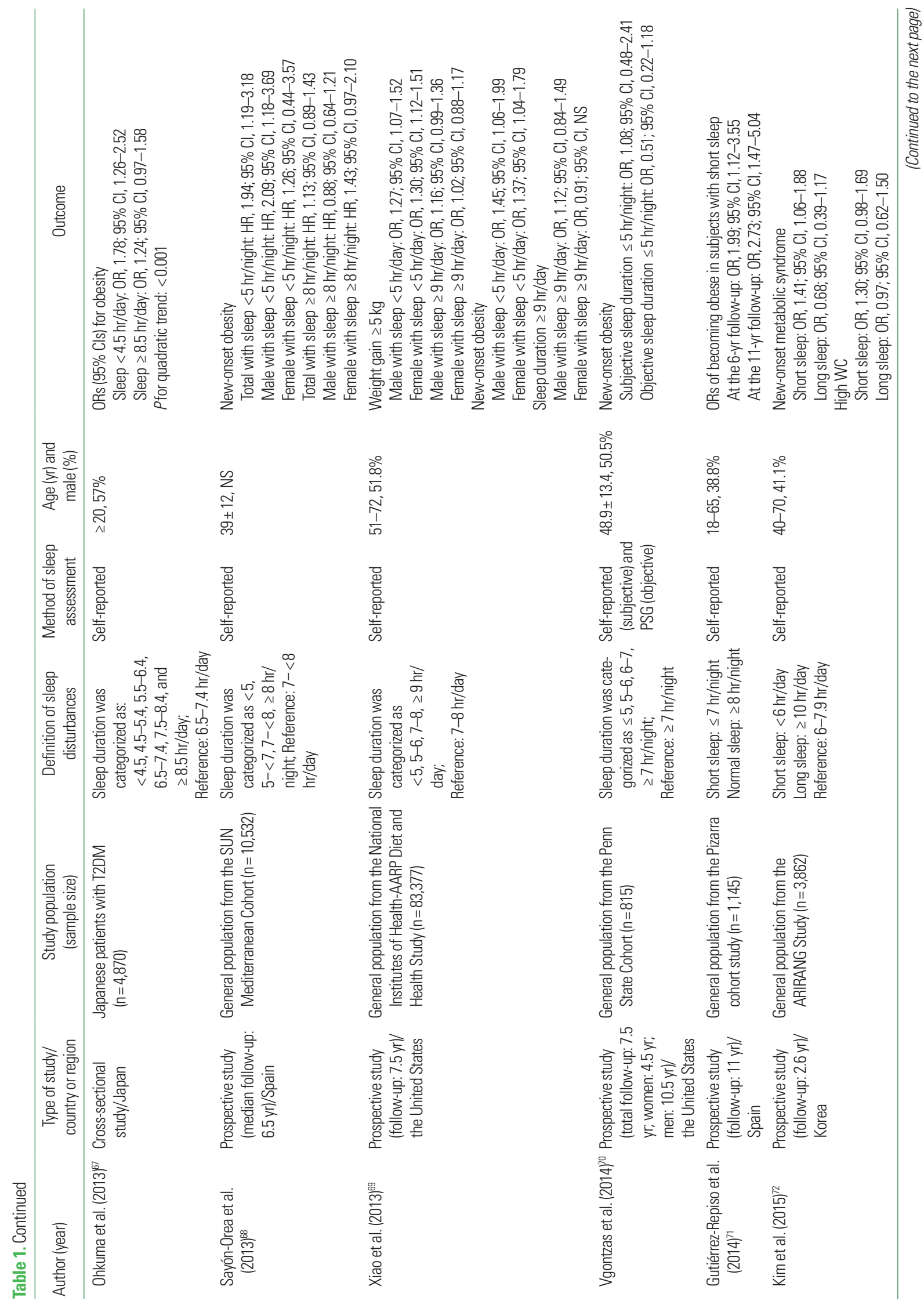




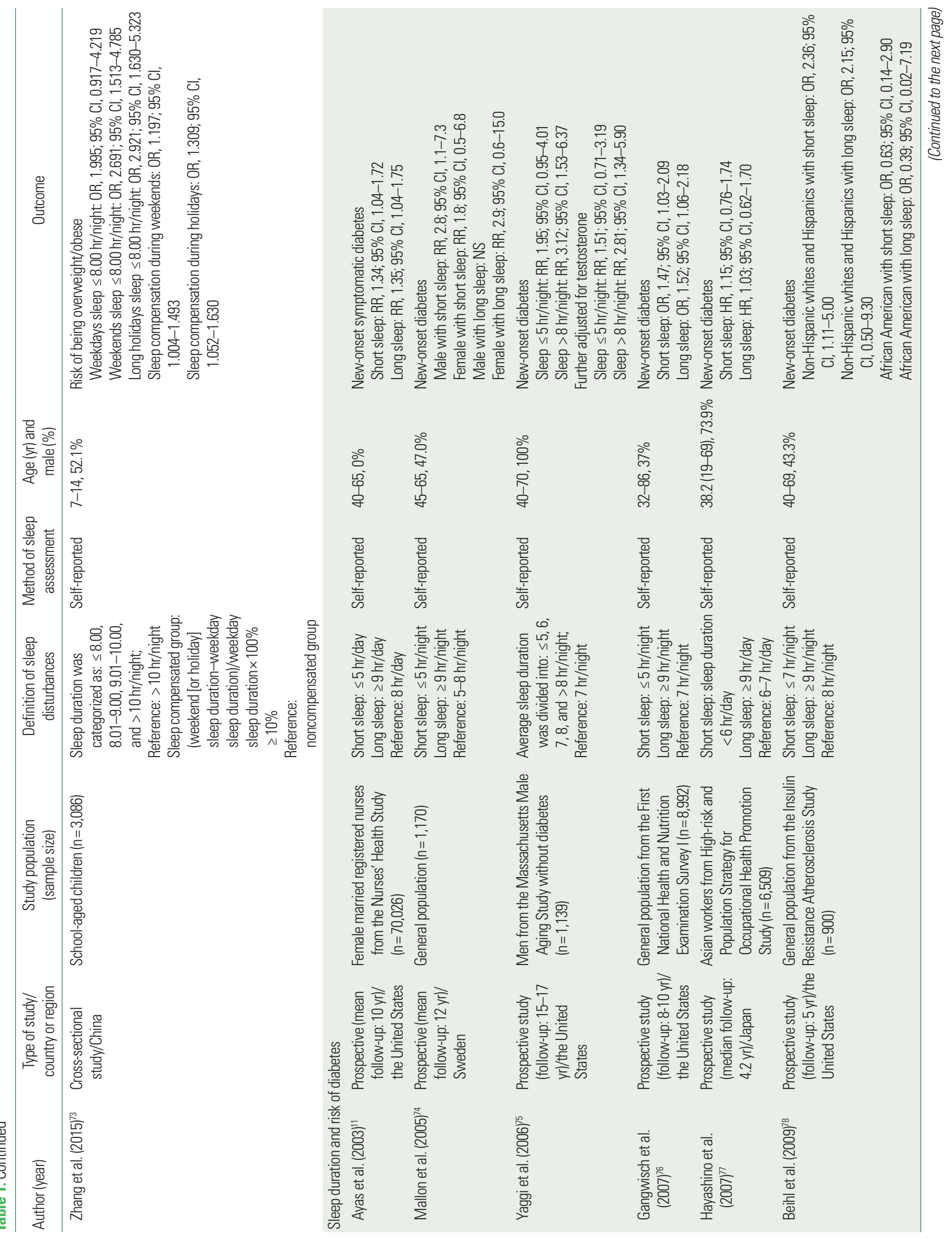




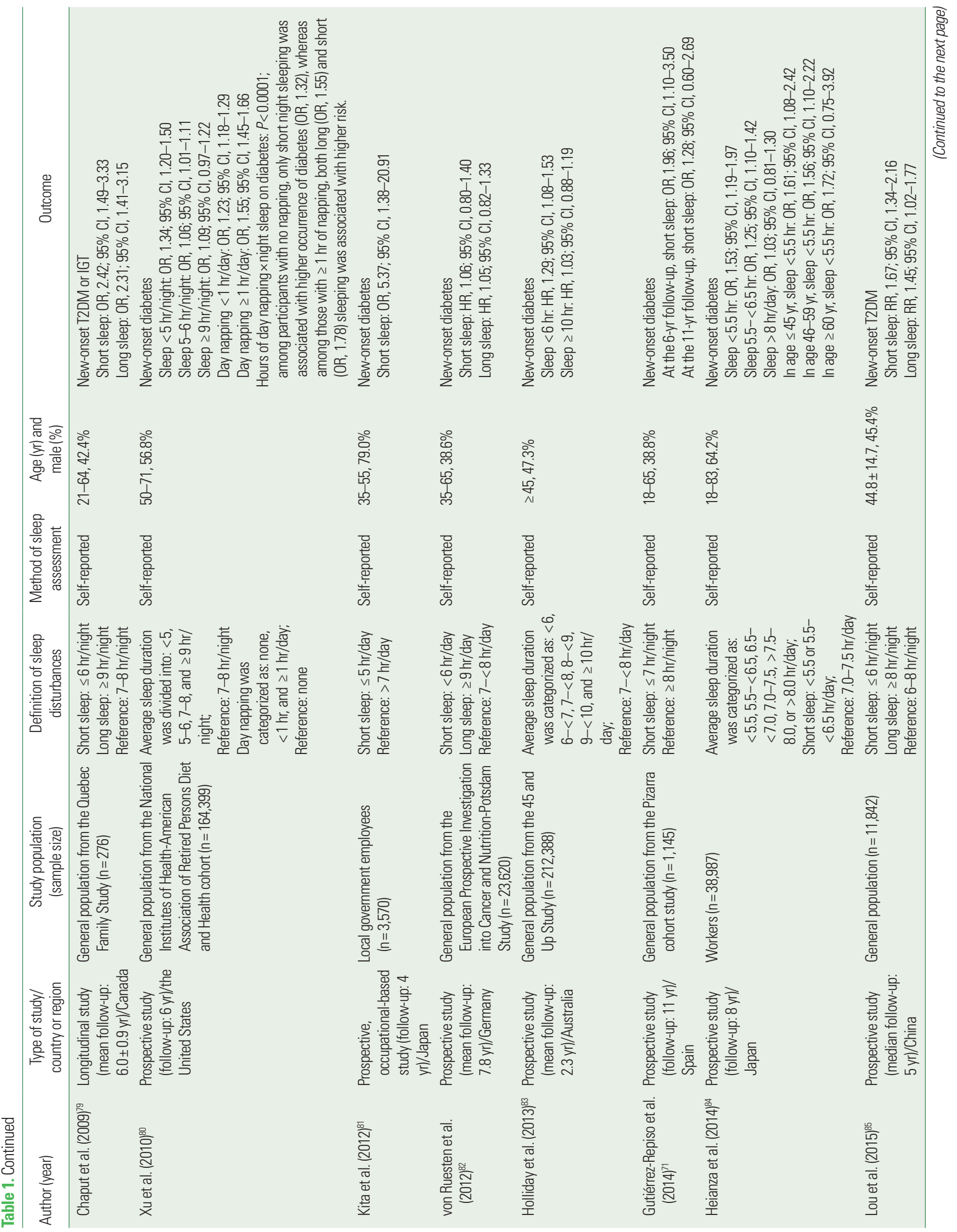




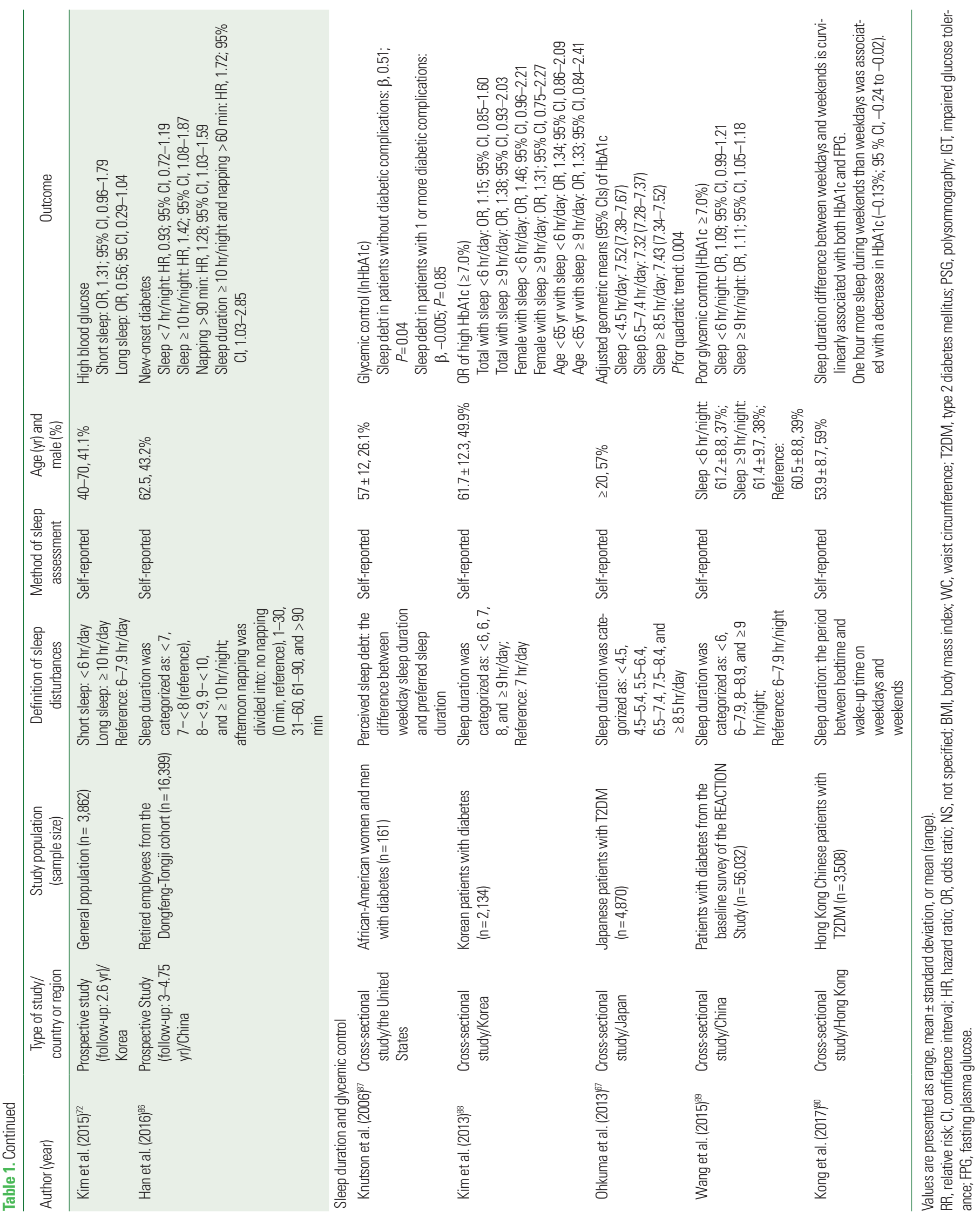




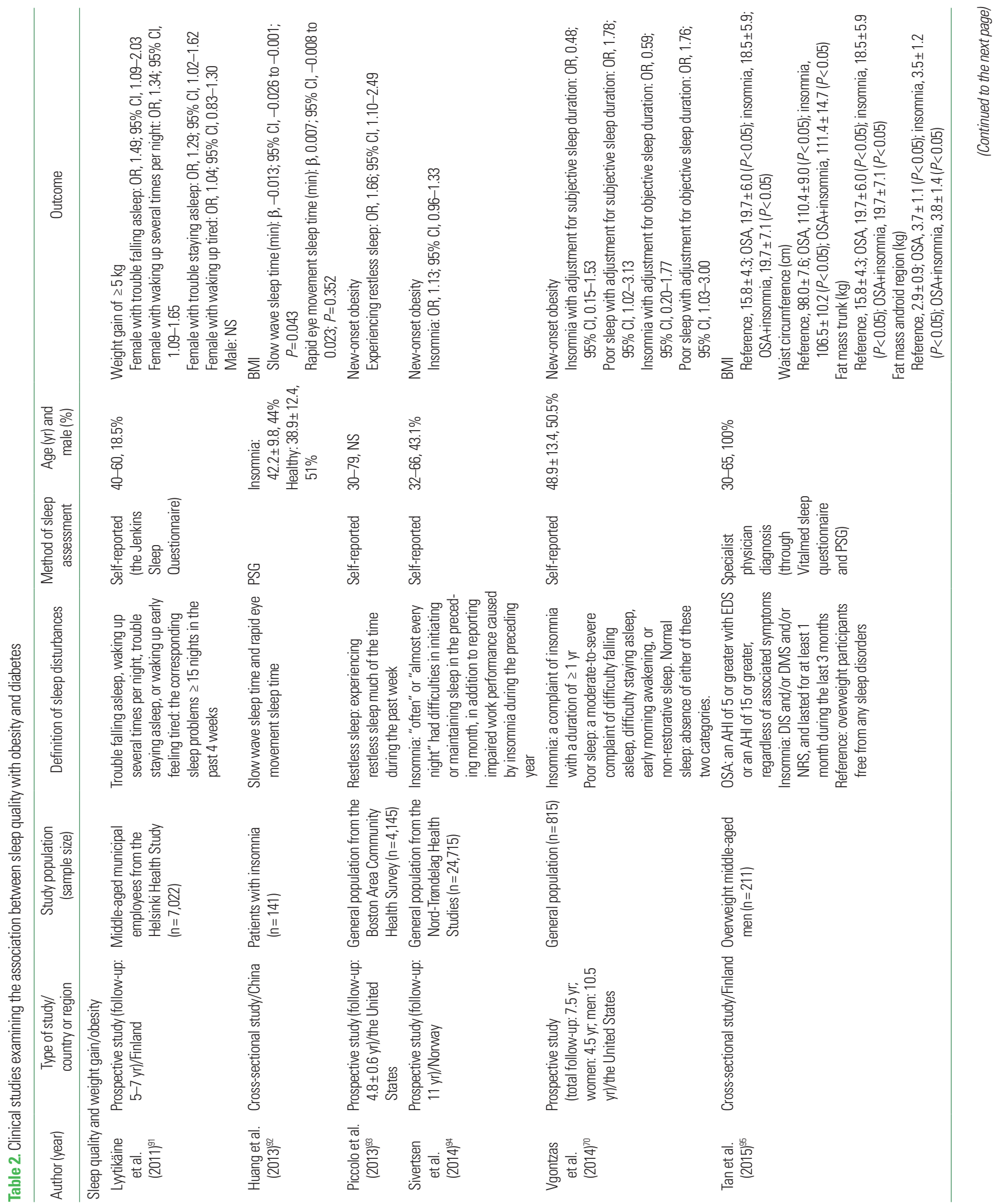




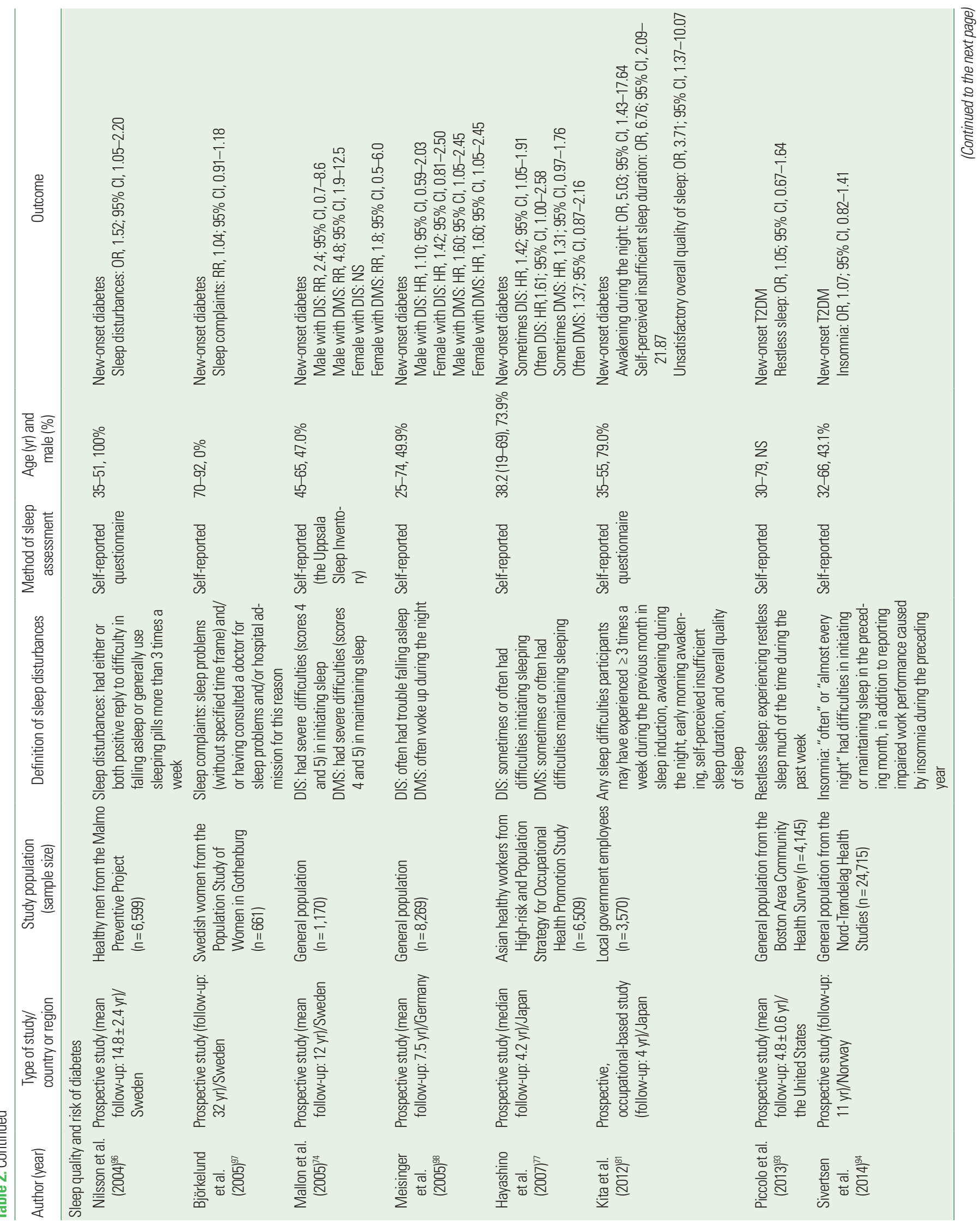




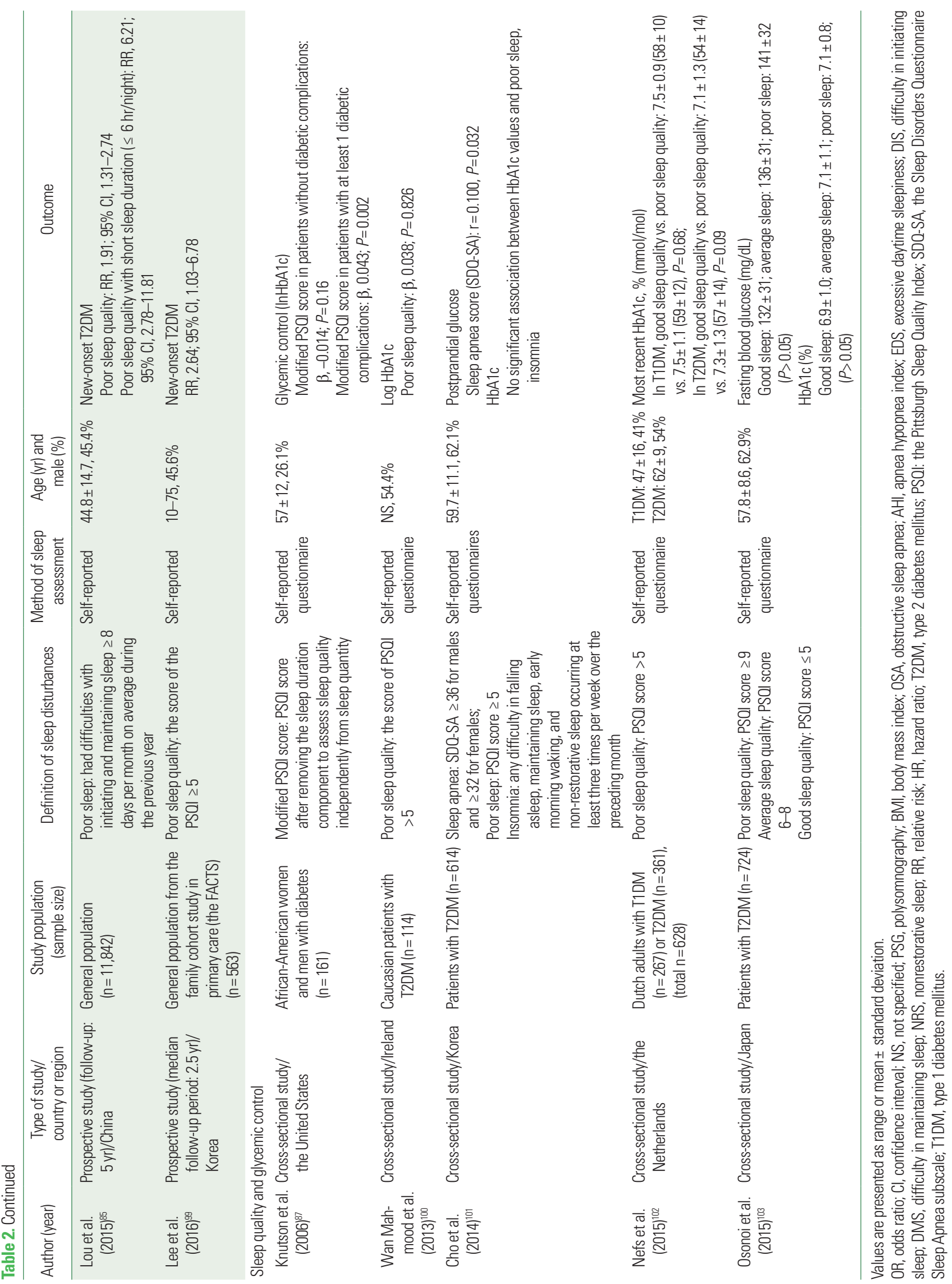


sleep (NRS) is also suggested by the International Classification of Sleep Disorders as a subtype of insomnia. ${ }^{104}$

Although the pathophysiology of insomnia is still not fully understood, it has long been considered to be a disorder of hyperarousal during both daytime and nighttime, which is associated with increased activation of whole-body and brain metabolism, hyperactivity of HPA axis and hormonal dysregulation. ${ }^{49} \mathrm{~A}$ study involving 1,042 monozygotic and 828 dizygotic twin pairs demonstrated a $10 \%$ phenotypic correlation between insomnia and obesity, suggesting a shared genetic mechanism that underlies these conditions. ${ }^{105}$ However, the findings about this association were inconsistent in other clinical studies, which mostly reported either no association or an inverse relationship between insomnia and BMI. In a cross-sectional study conducted in 211 Finnish men aged 30-65 years, among the overweight or obese participants $(n=163)$, those with insomnia $(n=40)$ had higher fat mass in the trunk and android regions than the group without sleep disorder $(n=76$, $P<0.05$ ), but no between-group differences in BMI or total fat mass. ${ }^{95}$ There was also no difference in BMI when comparing 141 Chinese patients with primary insomnia with 55 healthy volunteers $\left(22.54 \pm 2.76 \mathrm{~kg} / \mathrm{m}^{2}\right.$ vs. $\left.22.84 \pm 3.28 \mathrm{~kg} / \mathrm{m}^{2}, P=0.526\right) .{ }^{92}$ However, this study found that among patients with insomnia, there was a significant negative correlation between the amount of SWS and BMI after controlling for potential confounders $(\beta,-0.013$; $95 \%$ confidence interval $[\mathrm{CI}],-0.026$ to $-0.001 ; P=0.043)$, suggesting that impaired sleep quality in subjects with insomnia may be the culprit linking insomnia with obesity. By contrast, some researchers had reported positive relationships between insomnia and obesity indices. The prospective Helsinki Health Study which included 7,022 middle-aged respondents demonstrated that DIS (odds ratio [OR], 1.65; 95\% CI, 1.22-2.22) and DMS (OR, 1.41; 95\% CI, $1.13-1.75$ ) were associated with a weight gain of $5 \mathrm{~kg}$ or more after 5 to 7 years of follow-up, being more evident in women than in men..$^{91}$ In the prospective Penn State Cohort involving 815 nonobese adults with a follow-up duration of 7.5 years, a moderate to severe complaint of any DIS, DMS, EMA, or NRS was associated with an increased incidence of obesity (OR, 1.76-1.78), while insomnia tended towards significance after adjusted for sleep duration, emotional stress, and other potential confounders. ${ }^{70}$ Another prospective study conducted in Norwegian population $(\mathrm{n}=24,715)$ reported that insomnia was associated with an $18 \%$ increased risk (95\% CI, 1.06-1.33) of incident obesity after 11 years of follow up, which was independent of baseline demographics, anxiety and depression. However, this association was negated when further adjusted for other comorbidities, such as angina, T2DM and hypertension (OR, 1.09; 95\% CI, 0.97-1.24).94 Taken together, these inconclusive results may be related to the adoption of different definitions of insomnia and obesity.

Although conflicting results have been reported for obesity, it appears that most studies support an association between insomnia and diabetes risk. In a meta-analysis of 107,756 participants from 13 independent cohorts, those with insomnia had stronger association with incident diabetes (DIS: RR, 1.57; 95\% CI, 1.25-1.97; DMS: RR, 1.84; 95\% CI, 1.39-2.43), compared with participants with short sleep duration of $\leq 5-6$ hours per night (RR, 1.28; $95 \%$ CI, 1.03-1.60). ${ }^{106}$ In another larger meta-analysis of nearly 1.1 million participants from 36 studies, insomnia (RR, 1.38; 95\% CI, 1.18-1.62) and its subtypes (DIS: RR, 1.55; 95\% CI, 1.23-1.95; DMS: RR, 1.72; 95\% CI, 1.45-2.05) also demonstrated an independent association with excess risk of developing diabetes. ${ }^{107}$

Short sleep duration with coexistent insomnia may further aggravate the risk of future diabetes. In the Penn State Cohort of 1,741 participants, participants with insomnia and sleep curtailment ( < 5-hour per day) had an OR of 2.95 (95\% CI, 1.24-7.03) for diabetes after adjustment for age, race, sex, BMI, smoking, alcohol use, depression and sleep-disordered breathing, compared with those who had $>6$-hour sleep per day and without insomnia. ${ }^{108}$ Conversely, in the retrospective Freiburg Insomnia Cohort involving 328 patients with primary insomnia (203 women and 125 men; mean age, $44.3 \pm 12.2$ years), those with concomitant short sleep duration did not have increased risk of T2DM (OR, 1.39; 95\% CI, 0.34-5.67 for first night of short sleep and OR, 2.30; 95\% CI, 0.48-10.96 for second night of short sleep), perhaps due to a small number of patients with T2DM $(n=9) .{ }^{109}$ Indeed, there are possible pathogenetic mechanisms underpinning the link between insomnia and risk of diabetes, including reduction of glucose tolerance $^{40}$, alteration of HPA axis and sympathetic nervous system ${ }^{110}$, and elevated markers of chronic inflammation. ${ }^{111}$ Hence, well-designed studies with sufficient sample size are required to unravel the relationship between insomnia and diabetes. 


\section{SLEEP AND GENES REGULATING THE CIRCADIAN CLOCK}

Clock genes may play a key role in linking sleep and the effect of circadian disruptions on metabolic functions. ${ }^{23} \mathrm{~A}$ central clock which is located within the suprachiasmatic nuclei of the hypothalamus orchestrates the environmental light/dark cycles with human physiology and behavior. Genetic or environmental perturbations of this synchronized molecular mechanism can lead to metabolic disturbances. In the core clock mechanism, the brain and muscle Arnt like protein-1 (BMAL1)/circadian locomotor output cycles kaput (CLOCK) heterodimer binds to the E-box elements in the promoter regions of Per and Cry genes, thus activating their transcription proteins with feedback inhibition on the BMAL1/ CLOCK. ${ }^{112}$ Six hours of sleep curtailment was sufficient to reduce BMAL1 binding to the E-box elements of Per gene. ${ }^{23}$ Other important regulators that integrate the effects of circadian clock on metabolic pathways include the clock-controlled genes and certain transcription factors e.g., REV-ERB $\alpha$, retinoid-related orphan receptor $\alpha$, and peroxisome proliferator-activated receptor $\alpha^{2,113}$ These genes can also be categorized by type of regulations e.g., circadian cycle only (BMAL1), sleep-wake cycle only (Homer1a) or both (Per). Hence, the effects of sleep on gene expression, subsequent epigenetic modifications and metabolic perturbations require further translational research to improve our understanding about the genes involved and the details of the regulation. ${ }^{23}$

Coordination of the sleep/wake cycle as well as the metabolic and fasting/feeding cycle are all essential to maintain a normal circadian oscillatory system for healthy bodily functions. Glucose homeostasis is regulated by both the central clock that synchronizes sleep and feeding, and peripheral tissue clocks that coordinate one's behavior with glucose synthesis and utilization. ${ }^{114}$ When BMAL1/ CLOCK heterodimer colocalizes with the pancreatic transcription factor pancreatic and duodenal homeobox 1 on the regulatory sites of beta-cell cycling genes, pancreatic beta-cell maturation is enhanced with possible pulsatile insulin secretion according to the circadian rhythmicity. ${ }^{114}$ Similarly, BMAL1-ablation in mice reduces insulin exocytosis from pancreatic beta-cell, resulting in hyperglycemia. ${ }^{23}$ Based on the genome-wide association studies, individuals with $\mathrm{T} 2 \mathrm{DM}$ and melatonin receptor $1 \mathrm{~B}($ MTNR1B) risk allele may have high melatonin level that interacts with dietary intake, with subsequent impairment in glucose metabolism and increased risk of T2DM. ${ }^{23}$

Conditions that are often associated with circadian misalignment are shift work and trans-meridian air travel (jet lag). Shift work can desynchronize the central and peripheral circadian clocks, which further perturbs the glucose metabolism by decreasing insulin sensitivity, independent of sleep curtailment. ${ }^{23,115}$ In healthy adults, 3-week sleep curtailment with concomitant circadian misalignment is demonstrated to reduce the resting metabolic rate and impair pancreatic beta-cell secretion. ${ }^{116}$ In mice model, chronic jet lag disrupts the circadian cycle by uncoupling the central and peripheral clocks in the adipose tissue, and triggers leptin resistance leading to development of obesity, an effect independent of other risk factors. ${ }^{117}$ In the large prospective Nurses' Health Study 2, early chronotype combined with increasing years of rotating night shift work aggravated diabetes risk, even after adjustment for patients' attributes, family history of diabetes, diet, physical activity and self-reported sleep duration. ${ }^{118}$ Interestingly, late chronotype alone predicted a 51\% (hazard ratio, 1.51; 95\% CI, 1.13-2.03) excess risk of developing T2DM, which was attenuated by longer night shift exposure, presumably due to less interference to the "usual" circadian rhythm. ${ }^{118}$ These findings support the notion that chronotypeadapted work schedules can possibly reduce the circadian misalignment and prevent future cardiometabolic risk.

The circadian clock has been demonstrated to regulate the diurnal fluctuations of certain human metabolites such as the fatty acids and amino acids, independent of the fasting/feeding cycle. ${ }^{119}$ In the first human metabolomics study conducted during a 48-hour sleep/wake cycle, 27 of the 171 measured metabolites (e.g., fatty acids, tryptophan, taurine, and serotonin) were significantly elevated with sleep curtailment. ${ }^{120}$ This creates novel opportunities for potential therapeutic intervention targeting the key clock-regulated metabolic pathways and application of these noninvasive biomarkers for disease prediction and monitoring.

\section{CONCLUSION}

Good sleep hygiene is crucial to maintain optimal functions of the neuroendocrine and appetite regulation systems. To date, there 
is clear evidence in support of a causal relationship between sleep, circadian misalignment and cardiometabolic risk. Thus, health promotion campaigns should look beyond conventional strategies by emphasizing the pivotal role of improving sleep environment to curb the obesity epidemic. Nonetheless, there is a pressing need for future research to delineate the molecular intersections between sleep, circadian clock and metabolic pathways, as well as to explore potential preventive and therapeutic approaches to optimize sleep and circadian rhythm in predisposed individuals.

\section{CONFLICTS OF INTEREST}

The authors declare no conflict of interest.

\section{REFERENCES}

1. GBD 2015 Obesity Collaborators, Afshin A, Forouzanfar MH, Reitsma MB, Sur P, Estep K, et al. Health effects of overweight and obesity in 195 countries over 25 years. N Engl J Med 2017; 377:13-27.

2. McHill AW, Wright KP Jr. Role of sleep and circadian disruption on energy expenditure and in metabolic predisposition to human obesity and metabolic disease. Obes Rev 2017; 18 Suppl 1:15-24.

3. Iglowstein I, Jenni OG, Molinari L, Largo RH. Sleep duration from infancy to adolescence: reference values and generational trends. Pediatrics 2003;111:302-7.

4. Consensus Conference Panel, Watson NF, Badr MS, Belenky G, Bliwise DL, Buxton OM, et al. Joint consensus statement of the American Academy of Sleep Medicine and Sleep Research Society on the recommended amount of sleep for a healthy adult: methodology and discussion. Sleep 2015;38: 1161-83.

5. Paruthi S, Brooks LJ, D’Ambrosio C, Hall WA, Kotagal S, Lloyd RM, et al. Recommended amount of sleep for pediatric populations: a consensus statement of the American Academy of Sleep Medicine. J Clin Sleep Med 2016;12:785-6.

6. Lee SW, Ng KY, Chin WK. The impact of sleep amount and sleep quality on glycemic control in type 2 diabetes: a systematic review and meta-analysis. Sleep Med Rev 2017;31:
91-101

7. Liu Y, Wheaton AG, Chapman DP, Cunningham TJ, Lu H, Croft JB. Prevalence of healthy sleep duration among adults: United States, 2014. MMWR Morb Mortal Wkly Rep 2016; 65:137-41.

8. Cao XL, Wang SB, Zhong BL, Zhang L, Ungvari GS, Ng CH, et al. The prevalence of insomnia in the general population in China: a meta-analysis. PLoS One 2017;12:e0170772.

9. Bin YS, Marshall NS, Glozier N. Sleeping at the limits: the changing prevalence of short and long sleep durations in 10 countries. Am J Epidemiol 2013;177:826-33.

10. Jike M, Itani O, Watanabe N, Buysse DJ, Kaneita Y. Long sleep duration and health outcomes: a systematic review, meta-analysis and meta-regression. Sleep Med Rev $2017 \mathrm{Jul}$ 5 [Epub]. https://doi.org/10.1016/j.smrv.2017.06.011

11. Ayas NT, White DP, Al-Delaimy WK, Manson JE, Stampfer MJ, Speizer FE, et al. A prospective study of self-reported sleep duration and incident diabetes in women. Diabetes Care 2003;26:380-4.

12. Heymsfield SB, Wadden TA. Mechanisms, pathophysiology, and management of obesity. N Engl J Med 2017;376:25466.

13. Nakazato M, Murakami N, Date Y, Kojima M, Matsuo H, Kangawa $\mathrm{K}$, et al. A role for ghrelin in the central regulation of feeding. Nature 2001;409:194-8.

14. Zigman JM, Elmquist JK. Minireview: from anorexia to obesity. The yin and yang of body weight control. Endocrinology 2003;144:3749-56.

15. Dashti HS, Scheer FA, Jacques PF, Lamon-Fava S, Ordovás JM. Short sleep duration and dietary intake: epidemiologic evidence, mechanisms, and health implications. Adv Nutr 2015;6:648-59.

16. Colles SL, Dixon JB, O’Brien PE. Night eating syndrome and nocturnal snacking: association with obesity, binge eating and psychological distress. Int J Obes (Lond) 2007;31: 1722-30.

17. Kant AK, Graubard BI. Association of self-reported sleep duration with eating behaviors of American adults: NHANES 2005-2010. Am J Clin Nutr 2014;100:938-47.

18. Ding M, Keiley MK, Garza KB, Duffy PA, Zizza CA. Food 
insecurity is associated with poor sleep outcomes among US adults. J Nutr 2015;145:615-21.

19. St-Onge MP, Roberts AL, Chen J, Kelleman M, O’Keeffe M, RoyChoudhury A, et al. Short sleep duration increases energy intakes but does not change energy expenditure in normal-weight individuals. Am J Clin Nutr 2011;94:410-6.

20. Nedeltcheva AV, Kilkus JM, Imperial J, Kasza K, Schoeller DA, Penev PD. Sleep curtailment is accompanied by increased intake of calories from snacks. Am J Clin Nutr 2009; 89:126-33.

21. Shi Z, McEvoy M, Luu J, Attia J. Dietary fat and sleep duration in Chinese men and women. Int J Obes (Lond) 2008; 32:1835-40.

22. Dashti HS, Follis JL, Smith CE, Tanaka T, Cade BE, Gottlieb DJ, et al. Habitual sleep duration is associated with BMI and macronutrient intake and may be modified by CLOCK genetic variants. Am J Clin Nutr 2015;101:135-43.

23. Arble DM, Bass J, Behn CD, Butler MP, Challet E, Czeisler $\mathrm{C}$, et al. Impact of sleep and circadian disruption on energy balance and diabetes: a summary of workshop discussions. Sleep 2015;38:1849-60.

24. Taheri S, Lin L, Austin D, Young T, Mignot E. Short sleep duration is associated with reduced leptin, elevated ghrelin, and increased body mass index. PLoS Med 2004;1:e62.

25. Spiegel K, Leproult R, L'hermite-Balériaux M, Copinschi G, Penev PD, Van Cauter E. Leptin levels are dependent on sleep duration: relationships with sympathovagal balance, carbohydrate regulation, cortisol, and thyrotropin. J Clin Endocrinol Metab 2004;89:5762-71.

26. Greer SM, Goldstein AN, Walker MP. The impact of sleep deprivation on food desire in the human brain. Nat Commun 2013;4:2259.

27. St-Onge MP, Wolfe S, Sy M, Shechter A, Hirsch J. Sleep restriction increases the neuronal response to unhealthy food in normal-weight individuals. Int J Obes (Lond) 2014;38: 411-6.

28. Benedict C, Brooks SJ, O’Daly OG, Almèn MS, Morell A, Åberg K, et al. Acute sleep deprivation enhances the brain's response to hedonic food stimuli: an fMRI study. J Clin Endocrinol Metab 2012;97:E443-7.
29. Baron KG, Reid KJ, Kern AS, Zee PC. Role of sleep timing in caloric intake and BMI. Obesity (Silver Spring) 2011;19: 1374-81.

30. Stern JH, Grant AS, Thomson CA, Tinker L, Hale L, Brennan KM, et al. Short sleep duration is associated with decreased serum leptin, increased energy intake and decreased diet quality in postmenopausal women. Obesity (Silver Spring) 2014;22:E55-61.

31. Motivala SJ, Tomiyama AJ, Ziegler M, Khandrika S, Irwin MR. Nocturnal levels of ghrelin and leptin and sleep in chronic insomnia. Psychoneuroendocrinology 2009;34:540-5.

32. Spiegel K, Leproult R, Colecchia EF, L'Hermite-Balériaux M, Nie Z, Copinschi G, et al. Adaptation of the 24-h growth hormone profile to a state of sleep debt. Am J Physiol Regul Integr Comp Physiol 2000;279:R874-83.

33. Van Cauter E, Plat L, Copinschi G. Interrelations between sleep and the somatotropic axis. Sleep 1998;21:553-66.

34. Sandhu MS, Heald AH, Gibson JM, Cruickshank JK, Dunger DB, Wareham NJ. Circulating concentrations of insulinlike growth factor-I and development of glucose intolerance: a prospective observational study. Lancet 2002;359:1740-5.

35. Juul A, Scheike T, Davidsen M, Gyllenborg J, Jørgensen T. Low serum insulin-like growth factor I is associated with increased risk of ischemic heart disease: a population-based case-control study. Circulation 2002;106:939-44.

36. Sukhanov S, Higashi Y, Shai SY, Vaughn C, Mohler J, Li Y, et al. IGF-1 reduces inflammatory responses, suppresses oxidative stress, and decreases atherosclerosis progression in ApoEdeficient mice. Arterioscler Thromb Vasc Biol 2007;27:268490.

37. García-García F, Juárez-Aguilar E, Santiago-García J, Cardinali DP. Ghrelin and its interactions with growth hormone, leptin and orexins: implications for the sleep-wake cycle and metabolism. Sleep Med Rev 2014;18:89-97.

38. Gram IT, Norat T, Rinaldi S, Dossus L, Lukanova A, Téhard $\mathrm{B}$, et al. Body mass index, waist circumference and waist-hip ratio and serum levels of IGF-I and IGFBP-3 in European women. Int J Obes (Lond) 2006;30:1623-31.

39. Yeap BB, Chubb SA, Ho KK, Setoh JW, McCaul KA, Norman PE, et al. IGF1 and its binding proteins 3 and 1 are dif- 
ferentially associated with metabolic syndrome in older men. Eur J Endocrinol 2010;162:249-57.

40. Spiegel K, Leproult R, Van Cauter E. Impact of sleep debt on metabolic and endocrine function. Lancet 1999;354: 1435-9.

41. Fries E, Dettenborn L, Kirschbaum C. The cortisol awakening response (CAR): facts and future directions. Int J Psychophysiol 2009;72:67-73.

42. Kumari M, Badrick E, Ferrie J, Perski A, Marmot M, Chandola T. Self-reported sleep duration and sleep disturbance are independently associated with cortisol secretion in the Whitehall II study. J Clin Endocrinol Metab 2009;94:4801-9.

43. Huang T, Poole EM, Vetter C, Rexrode KM, Kubzansky LD, Schernhammer E, et al. Habitual sleep quality and diurnal rhythms of salivary cortisol and dehydroepiandrosterone in postmenopausal women. Psychoneuroendocrinology 2017; 84:172-80.

44. Zhang J, Ma RC, Kong AP, So WY, Li AM, Lam SP, et al. Relationship of sleep quantity and quality with 24-hour urinary catecholamines and salivary awakening cortisol in healthy middle-aged adults. Sleep 2011;34:225-33.

45. Lemola S, Perkinson-Gloor N, Hagmann-von Arx P, Brand S, Holsboer-Trachsler E, Grob A, et al. Morning cortisol secretion in school-age children is related to the sleep pattern of the preceding night. Psychoneuroendocrinology 2015;52: 297-301.

46. Räikkönen K, Matthews KA, Pesonen AK, Pyhälä R, Paavonen EJ, Feldt K, et al. Poor sleep and altered hypothalamic-pituitary-adrenocortical and sympatho-adrenal-medullary system activity in children. J Clin Endocrinol Metab 2010; 95:2254-61.

47. Rao MN, Blackwell T, Redline S, Punjabi NM, Barrett-Connor E, Neylan TC, et al. Association between sleep duration and 24-hour urine free cortisol in the MrOS Sleep Study. PLoS One 2013;8:e75205.

48. Richardson GS. Human physiological models of insomnia. Sleep Med 2007;8 Suppl 4:S9-14.

49. Bonnet MH, Arand DL. Hyperarousal and insomnia: state of the science. Sleep Med Rev 2010;14:9-15.

50. Zhang J, Lam SP, Li SX, Ma RC, Kong AP, Chan MH, et al.
A community-based study on the association between insomnia and hypothalamic-pituitary-adrenal axis: sex and pubertal influences. J Clin Endocrinol Metab 2014;99:2277-87. 51. Irwin M, Thompson J, Miller C, Gillin JC, Ziegler M. Effects of sleep and sleep deprivation on catecholamine and interleukin-2 levels in humans: clinical implications. J Clin Endocrinol Metab 1999;84:1979-85.

52. Lusardi P, Zoppi A, Preti P, Pesce RM, Piazza E, Fogari R. Effects of insufficient sleep on blood pressure in hypertensive patients: a 24-h study. Am J Hypertens 1999;12(1 Pt $1): 63-8$.

53. Broussard JL, Ehrmann DA, Van Cauter E, Tasali E, Brady MJ. Impaired insulin signaling in human adipocytes after experimental sleep restriction: a randomized, crossover study. Ann Intern Med 2012;157:549-57.

54. Kong AP, Wing YK, Choi KC, Li AM, Ko GT, Ma RC, et al. Associations of sleep duration with obesity and serum lipid profile in children and adolescents. Sleep Med 2011;12:65965.

55. Zhan Y, Chen R, Yu J. Sleep duration and abnormal serum lipids: the China Health and Nutrition Survey. Sleep Med 2014;15:833-9.

56. Patel SR, Malhotra A, White DP, Gottlieb DJ, Hu FB. Association between reduced sleep and weight gain in women. Am J Epidemiol 2006;164:947-54.

57. Chaput JP, Després JP, Bouchard C, Tremblay A. The association between sleep duration and weight gain in adults: a 6-year prospective study from the Quebec Family Study. Sleep 2008;31:517-23.

58. López-García E, Faubel R, León-Muñoz L, Zuluaga MC, Banegas JR, Rodríguez-Artalejo F. Sleep duration, general and abdominal obesity, and weight change among the older adult population of Spain. Am J Clin Nutr 2008;87:310-6.

59. Stranges S, Cappuccio FP, Kandala NB, Miller MA, Taggart FM, Kumari M, et al. Cross-sectional versus prospective associations of sleep duration with changes in relative weight and body fat distribution: the Whitehall II Study. Am J Epidemiol 2008;167:321-9.

60. Nishiura C, Noguchi J, Hashimoto H. Dietary patterns only partially explain the effect of short sleep duration on the in- 
cidence of obesity. Sleep 2010;33:753-7.

61. Watanabe M, Kikuchi H, Tanaka K, Takahashi M. Association of short sleep duration with weight gain and obesity at 1-year follow-up: a large-scale prospective study. Sleep 2010; 33:161-7.

62. Itani O, Kaneita Y, Murata A, Yokoyama E, Ohida T. Association of onset of obesity with sleep duration and shift work among Japanese adults. Sleep Med 2011;12:341-5.

63. Lyytikäinen P, Rahkonen O, Lahelma E, Lallukka T. Association of sleep duration with weight and weight gain: a prospective follow-up study. J Sleep Res 2011;20:298-302.

64. Kobayashi D, Takahashi O, Deshpande GA, Shimbo T, Fukui T. Association between weight gain, obesity, and sleep duration: a large-scale 3-year cohort study. Sleep Breath 2012;16:829-33.

65. Yiengprugsawan V, Banwell C, Seubsman SA, Sleigh AC; Thai Cohort Study Team. Short sleep and obesity in a large national cohort of Thai adults. BMJ Open 2012;2:e000561.

66. Nagai M, Tomata Y, Watanabe T, Kakizaki M, Tsuji I. Association between sleep duration, weight gain, and obesity for long period. Sleep Med 2013;14:206-10.

67. Ohkuma T, Fujii H, Iwase M, Kikuchi Y, Ogata S, Idewaki Y, et al. Impact of sleep duration on obesity and the glycemic level in patients with type 2 diabetes: the Fukuoka Diabetes Registry. Diabetes Care 2013;36:611-7.

68. Sayón-Orea C, Bes-Rastrollo M, Carlos S, Beunza JJ, Basterra-Gortari FJ, Martínez-González MA. Association between sleeping hours and siesta and the risk of obesity: the SUN Mediterranean Cohort. Obes Facts 2013;6:337-47.

69. Xiao Q, Arem H, Moore SC, Hollenbeck AR, Matthews CE. A large prospective investigation of sleep duration, weight change, and obesity in the NIH-AARP Diet and Health Study cohort. Am J Epidemiol 2013;178:1600-10.

70. Vgontzas AN, Fernandez-Mendoza J, Miksiewicz T, Kritikou I, Shaffer ML, Liao D, et al. Unveiling the longitudinal association between short sleep duration and the incidence of obesity: the Penn State Cohort. Int J Obes (Lond) 2014;38: 825-32.

71. Gutiérrez-Repiso C, Soriguer F, Rubio-Martín E, Esteva de Antonio I, Ruiz de Adana MS, Almaraz MC, et al. Night- time sleep duration and the incidence of obesity and type 2 diabetes: findings from the prospective Pizarra study. Sleep Med 2014;15:1398-404.

72. Kim JY, Yadav D, Ahn SV, Koh SB, Park JT, Yoon J, et al. A prospective study of total sleep duration and incident metabolic syndrome: the ARIRANG study. Sleep Med 2015;16: 1511-5.

73. Zhang B, Hao Y, Zhou J, Jia F, Li X, Tang Y, et al. The association between sleep patterns and overweight/obesity in Chinese children: a cross-sectional study. Neuropsychiatr Dis Treat 2015;11:2209-16.

74. Mallon L, Broman JE, Hetta J. High incidence of diabetes in men with sleep complaints or short sleep duration: a 12-year follow-up study of a middle-aged population. Diabetes Care 2005;28:2762-7.

75. Yaggi HK, Araujo AB, McKinlay JB. Sleep duration as a risk factor for the development of type 2 diabetes. Diabetes Care 2006;29:657-61.

76. Gangwisch JE, Heymsfield SB, Boden-Albala B, Buijs RM, Kreier F, Pickering TG, et al. Sleep duration as a risk factor for diabetes incidence in a large U.S. sample. Sleep 2007;30: 1667-73.

77. Hayashino Y, Fukuhara S, Suzukamo Y, Okamura T, Tanaka T, Ueshima $\mathrm{H}$, et al. Relation between sleep quality and quantity, quality of life, and risk of developing diabetes in healthy workers in Japan: the High-risk and Population Strategy for Occupational Health Promotion (HIPOP-OHP) Study. BMC Public Health 2007;7:129.

78. Beihl DA, Liese AD, Haffner SM. Sleep duration as a risk factor for incident type 2 diabetes in a multiethnic cohort. Ann Epidemiol 2009;19:351-7.

79. Chaput JP, Després JP, Bouchard C, Astrup A, Tremblay A. Sleep duration as a risk factor for the development of type 2 diabetes or impaired glucose tolerance: analyses of the Quebec Family Study. Sleep Med 2009;10:919-24.

80. Xu Q, Song Y, Hollenbeck A, Blair A, Schatzkin A, Chen H. Day napping and short night sleeping are associated with higher risk of diabetes in older adults. Diabetes Care 2010; 33:78-83.

81. Kita T, Yoshioka E, Satoh H, Saijo Y, Kawaharada M, Okada 
E, et al. Short sleep duration and poor sleep quality increase the risk of diabetes in Japanese workers with no family history of diabetes. Diabetes Care 2012;35:313-8.

82. von Ruesten A, Weikert C, Fietze I, Boeing H. Association of sleep duration with chronic diseases in the European Prospective Investigation into Cancer and Nutrition (EPIC)Potsdam study. PLoS One 2012;7:e30972.

83. Holliday EG, Magee CA, Kritharides L, Banks E, Attia J. Short sleep duration is associated with risk of future diabetes but not cardiovascular disease: a prospective study and meta-analysis. PLoS One 2013;8:e82305.

84. Heianza Y, Kato K, Fujihara K, Tanaka S, Kodama S, Hanyu $\mathrm{O}$, et al. Role of sleep duration as a risk factor for type 2 diabetes among adults of different ages in Japan: the Niigata Wellness Study. Diabet Med 2014;31:1363-7.

85. Lou P, Zhang P, Zhang L, Chen P, Chang G, Zhang N, et al. Effects of sleep duration and sleep quality on prevalence of type 2 diabetes mellitus: a 5-year follow-up study in China. Diabetes Res Clin Pract 2015;109:178-84.

86. Han X, Liu B, Wang J, Pan A, Li Y, Hu H, et al. Long sleep duration and afternoon napping are associated with higher risk of incident diabetes in middle-aged and older Chinese: the Dongfeng-Tongji cohort study. Ann Med 2016;48:21623.

87. Knutson KL, Ryden AM, Mander BA, Van Cauter E. Role of sleep duration and quality in the risk and severity of type 2 diabetes mellitus. Arch Intern Med 2006;166:1768-74.

88. Kim BK, Kim BS, An SY, Lee MS, Choi YJ, Han SJ, et al. Sleep duration and glycemic control in patients with diabetes mellitus: Korea National Health and Nutrition Examination Survey 2007-2010. J Korean Med Sci 2013;28:1334-9.

89. Wang T, Lu J, Wang W, Mu Y, Zhao J, Liu C, et al. Sleep duration and snoring associate with hypertension and glycaemic control in patients with diabetes. Diabet Med 2015;32: 1001-7.

90. Kong AP, Choi KC, Zhang J, Luk A, Lam SP, Chan MH, et al. Curvilinear associations of sleep patterns during weekdays and weekends with glycemic control in type 2 diabetes: the Hong Kong Diabetes Registry. Acta Diabetol 2017;54: $151-62$.
91. Lyytikäinen P, Lallukka T, Lahelma E, Rahkonen O. Sleep problems and major weight gain: a follow-up study. Int J Obes (Lond) 2011;35:109-14.

92. Huang L, Zhou J, Sun Y, Li Z, Lei F, Zhou G, et al. Polysomnographically determined sleep and body mass index in patients with insomnia. Psychiatry Res 2013;209:540-4.

93. Piccolo RS, Yang M, Bliwise DL, Yaggi HK, Araujo AB. Racial and socioeconomic disparities in sleep and chronic disease: results of a longitudinal investigation. Ethn Dis 2013; 23:499-507.

94. Sivertsen B, Lallukka T, Salo P, Pallesen S, Hysing M, Krokstad $\mathrm{S}$, et al. Insomnia as a risk factor for ill health: results from the large population-based prospective HUNT Study in Norway. J Sleep Res 2014;23:124-32.

95. Tan X, Alén M, Cheng SM, Mikkola TM, Tenhunen J, Lyytikäinen A, et al. Associations of disordered sleep with body fat distribution, physical activity and diet among overweight middle-aged men. J Sleep Res 2015;24:414-24.

96. Nilsson PM, Rööst M, Engström G, Hedblad B, Berglund G. Incidence of diabetes in middle-aged men is related to sleep disturbances. Diabetes Care 2004;27:2464-9.

97. Björkelund C, Bondyr-Carlsson D, Lapidus L, Lissner L, Månsson J, Skoog I, et al. Sleep disturbances in midlife unrelated to 32-year diabetes incidence: the prospective population study of women in Gothenburg. Diabetes Care 2005; 28:2739-44.

98. Meisinger C, Heier M, Loewel H; MONICA/KORA Augsburg Cohort Study. Sleep disturbance as a predictor of type 2 diabetes mellitus in men and women from the general population. Diabetologia 2005;48:235-41.

99. Lee JA, Sunwoo S, Kim YS, Yu BY, Park HK, Jeon TH, et al. The effect of sleep quality on the development of type $2 \mathrm{di}$ abetes in primary care patients. J Korean Med Sci 2016;31: 240-6.

100. Wan Mahmood WA, Draman Yusoff MS, Behan LA, Di Perna A, Kyaw Tun T, McDermott J, et al. Association between sleep disruption and levels of lipids in Caucasians with type 2 diabetes. Int J Endocrinol 2013;2013:341506.

101. Cho EH, Lee H, Ryu OH, Choi MG, Kim SW. Sleep disturbances and glucoregulation in patients with type 2 diabetes. 
J Korean Med Sci 2014;29:243-7.

102. Nefs G, Donga E, van Someren E, Bot M, Speight J, Pouwer F. Subjective sleep impairment in adults with type 1 or type 2 diabetes: results from diabetes MILES-The Netherlands. Diabetes Res Clin Pract 2015;109:466-75.

103. Osonoi Y, Mita T, Osonoi T, Saito M, Tamasawa A, Nakayama $\mathrm{S}$, et al. Poor sleep quality is associated with increased arterial stiffness in Japanese patients with type 2 diabetes mellitus. BMC Endocr Disord 2015;15:29.

104. American Academy of Sleep Medicine. International classification of sleep disorders. Darien (IL): American Academy of Sleep Medicine; 2014.

105. Watson NF, Goldberg J, Arguelles L, Buchwald D. Genetic and environmental influences on insomnia, daytime sleepiness, and obesity in twins. Sleep 2006;29:645-9.

106. Cappuccio FP, D’Elia L, Strazzullo P, Miller MA. Quantity and quality of sleep and incidence of type 2 diabetes: a systematic review and meta-analysis. Diabetes Care 2010;33: 414-20.

107. Anothaisintawee T, Reutrakul S, Van Cauter E, Thakkinstian A. Sleep disturbances compared to traditional risk factors for diabetes development: systematic review and meta-analysis. Sleep Med Rev 2016;30:11-24.

108. Vgontzas AN, Liao D, Pejovic S, Calhoun S, Karataraki M, Bixler EO. Insomnia with objective short sleep duration is associated with type 2 diabetes: a population-based study. Diabetes Care 2009;32:1980-5.

109. Johann AF, Hertenstein E, Kyle SD, Baglioni C, Feige B, Nissen $\mathrm{C}$, et al. Insomnia with objective short sleep duration is associated with longer duration of insomnia in the Freiburg Insomnia Cohort compared to insomnia with normal sleep duration, but not with hypertension. PLoS One 2017;12: e0180339.

110. Vgontzas AN, Chrousos GP. Sleep, the hypothalamic-pituitary-adrenal axis, and cytokines: multiple interactions and disturbances in sleep disorders. Endocrinol Metab Clin North Am 2002;31:15-36.

111. Mullington JM, Haack M, Toth M, Serrador JM, Meier-Ewert HK. Cardiovascular, inflammatory, and metabolic consequences of sleep deprivation. Prog Cardiovasc Dis 2009;51: 294-302.

112. Partch CL, Green CB, Takahashi JS. Molecular architecture of the mammalian circadian clock. Trends Cell Biol 2014; 24:90-9.

113. Albrecht U. The circadian clock, metabolism and obesity. Obes Rev 2017;18 Suppl 1:25-33.

114. Perelis M, Marcheva B, Ramsey KM, Schipma MJ, Hutchison $\mathrm{AL}$, Taguchi $\mathrm{A}$, et al. Pancreatic $\beta$ cell enhancers regulate rhythmic transcription of genes controlling insulin secretion. Science 2015;350:aac4250.

115. Leproult R, Holmbäck U, Van Cauter E. Circadian misalignment augments markers of insulin resistance and inflammation, independently of sleep loss. Diabetes 2014;63:1860-9.

116. Buxton OM, Cain SW, O'Connor SP, Porter JH, Duffy JF, Wang W, et al. Adverse metabolic consequences in humans of prolonged sleep restriction combined with circadian disruption. Sci Transl Med 2012;4:129ra43.

117. Kettner NM, Mayo SA, Hua J, Lee C, Moore DD, Fu L. Circadian dysfunction induces leptin resistance in mice. Cell Metab 2015;22:448-59.

118. Vetter C, Devore EE, Ramin CA, Speizer FE, Willett WC, Schernhammer ES. Mismatch of sleep and work timing and risk of type 2 diabetes. Diabetes Care 2015;38:1707-13.

119. Dallmann R, Viola AU, Tarokh L, Cajochen C, Brown SA. The human circadian metabolome. Proc Natl Acad Sci U S A 2012;109:2625-9.

120. Davies SK, Ang JE, Revell VL, Holmes B, Mann A, Robertson FP, et al. Effect of sleep deprivation on the human metabolome. Proc Natl Acad Sci U S A 2014;111:10761-6. 